\title{
Corrosion Measursement, Friction testing and XRD Analysis of Single Layer CrN Coatings on AISI 304 Stainless Steel
}

\author{
Alok Vats \\ M. Tech, Production Engineering, MNIT Jaipur, Pass out 2016 \\ Address: Plot No. 761 Mundka, New Delhi- 110041 (Near Swati Modern Public School)
}

\begin{abstract}
The purpose of present study was to investigate the erosive corrosive wear behavior of single layer (CrN) coatings on AISI 304 Stainless Steel samples with varying coating thickness $(0-200 \mathrm{~nm})$ in the range of $50 \mathrm{~nm}$. The slurry jet erosive test was conducted on Slurry Jet Erosion Tester in saline slurry (3.5wt\% salt) under the different working conditions with varying impact velocity $(10-25 \mathrm{~m} / \mathrm{s})$, impingement angle $\left(30^{\circ}-75^{\circ}\right)$ and erodent discharge (160-280 $\mathrm{gm} / \mathrm{min})$. Corrosion tests were conducted in 3.5 wt. \% $\mathrm{NaCl}$ solution using a Potentiostat, in order to analyze the corrosion behavior of the coated samples in sea water environment. Coefficient of friction was measured using a Scratch Tester. XRD analysis of the eroded samples indicated the presence of both $\mathrm{CrN}$ and $\mathrm{Cr}_{2} \mathrm{~N}$ (200) in the coatings.
\end{abstract}

Keywords-Erosive -corrosive wear, single layer coating, Potentiostat, Coefficient of friction, XRD analysis.

\section{INTRODUCTION}

Erosion-corrosion is the increase in the rate of degradation of the material caused by the combined action of electrochemical corrosion and mechanical wear processes. Corrosion is a material degradation process which occurs due to electrochemical action, while erosion is a mechanical wear process. When these two processes act together especially in the marine environments, it is known as erosion-corrosion. It is one of the major causes of failure in the nuclear power plants, chemical, petrochemical industries and marine environments where combined effect of erosion and corrosion phenomena occurs. In the marine field, this study applies to ship and boats. The study is equally beneficial in those areas where the underground salty water is supplied for household purposes, and the same has to be delivered to the overhead tank.

In the liquid- particle flow, the sand particles get impinged on steel surface which remove a layer of protective film from its surface. The chloride ions act rapidly on the exposed surface having discontinuity. In this way pure erosion and erosion enhanced corrosion are the dominant mechanisms that degrade the metal surface in erosion corrosion [1-6]. In order to improve the physical, mechanical and surface wear of metal such as steel, surface treatment such as modification of surface using silane, electroplating, Nitriding and coating etc are used [7-13]. A majority of surface modification lead to improved corrosive characteristics of the steel. Hence, they are also called corrosion inhibitors and are used on variety of steels. Neville et al. [7] studied erosioncorrosion of engineering steels by the use of chemicals on X65 pipeline steel, $13 \mathrm{Cr}$ martensitic stainless steel and super-duplex stainless steels. They concluded that inhibitor has a greater effect on the corrosion component of carbon steel but offers no protection on super-duplex stainless steel under the conditions tested. In another research, $\mathrm{Hu}$ et al.[14] assessed the effect of corrosion inhibitor on erosion-corrosion of API-5L-X65 stainless steel in multi-phase jet impingement conditions and found that corrosion inhibitor provides up to $20 \%$ protection in erosion-corrosion conditions and that oil phase reduces the erosion component by reducing the particle velocity in the flow conditions. Yao et al. [15] investigated a new method for protecting bends from erosion in gas-particle flows and reported that adding ribs on the outer-wall of the inside bend can significantly improve bend's erosion protection ability. Surface coating technology has also been deployed to enhance the erosive corrosive characteristics of the metals. Multilayer coatings offer protection against synergistic effects on bare stainless steel surfaces.

Corrosion resistance can also be increased by providing an interlayer of a suitable material [16]. Coatings of $\mathrm{CrN}$ and $\mathrm{CrCN}$ have been commonly used in industry and research to improve surface properties of materials. However, $\mathrm{CrCN}$ coatings provide better corrosion resistance than $\mathrm{CrN}$ coated samples due to its superior mechanical properties [17]. Shan et al. [18] fabricated CrN coatings on $316 \mathrm{~L}$ stainless steel substrate by multiarc ion plating system, performed Polarization tests and 
concluded that the multilayer structure could limit the crack propagation only to the layer and reduce cracks in the coating. However, there are various other factors besides the coating thickness that affect the erosive corrosive performance under practical conditions. These are impact velocity, impingement angle and erodent discharge respectively. The erosive corrosive performance of the material under a given combination of these factors has not been fully understood.

The aim of this work is to measure corrosion, calculate the coefficient of friction and perform XRD analysis of single layer CrN coatings on AISI 304 Stainless Steel.

\section{EXPERIMENTAL PROCEDURE}

\subsection{Materials}

The proposed work consists of deposition of monolayered PVD coatings of $\mathrm{CrN}$ of varying thickness on AISI 304 stainless steel. AISI 304 stainless steel was purchased from Bahubali Steels, New Delhi. While Chromium powder was procured from $\mathrm{M} / \mathrm{s}$ Indian Diamond Tools and M/s Scientific Instruments, Jaipur, India.

\subsection{Sample Preparation and Coating Process}

The samples for coating were prepared as per test standard specification with the help of a diamond cutter. Then the uncoated samples were mirror-polished using a MetaServe 250 Grinder Polisher (Buhler machine, Illinois, USA). The fine polish provides the improvement of adherence between coating and the samples. Before coating, samples were cleaned in acetone and then dried in a pre-vacuum dryer. The pellets used for coating were prepared with the help of $99.5 \%$ pure Cr powder procured from M/s Indian Diamond Tools and M/s Scientific Instruments, Jaipur. The pellet were pressed using a $\mathrm{KBr}$ press at a pressure of 15 tonnes.

A thermal Vapor deposition process (inside a high temperature Vacuum Box Coater -Model BC-300, Hind High Vacuum Co. (P) Ltd. Bangalore, India) (Figure.1) was used to fabricate single layer (chromium nitride) coated AISI 304 Stainless Steel with varying coatings thickness $(50 \mathrm{~nm}, 100 \mathrm{~nm}, 150 \mathrm{~nm}$ and $200 \mathrm{~nm})$. In this coating process, a sample of AISI 304 Stainless Steel was first positioned in the sample holder. Then a tungsten filament was used to hold the pellet of pure chromium. A high vacuum of $10^{-3}$ bar was created inside the chamber and current (50-75 A, $12 \mathrm{~V}$ ) was supplied to the tungsten filament to evaporate pure chromium. Then, nitrogen gas was allowed to flow in the chamber which reacted with the evaporated chromium and a layer of chromium nitride was deposited on the surface of the AISI 304 Stainless Steel. Coating thickness was maintained as $50 \mathrm{~nm}, 100 \mathrm{~nm}$, $150 \mathrm{~nm}$ and $200 \mathrm{~nm}$. Four different coatings were developed. Parameters for $\mathrm{CrN}$ coating were taken as coating rate- $0.1 \AA / \mathrm{sec}$, coating thickness-200nm, Vacuum Chamber temperature- $2000^{\circ} \mathrm{C}$, Vacuum Pressure- $1.2 \times 10^{-6}$ bar, Nitrogen flow rate- $50 \mathrm{cc} / \mathrm{min}$, Voltage- $12 \mathrm{~V}$, Current39 Ampere.

\subsection{Sample characterization}

\subsubsection{Slurry Jet Erosion Test}

The slurry erosion behavior of single layer $\mathrm{CrN}$ coated and uncoated samples was evaluated using a Slurry Jet Erosion Tester (Model TR411, Ducom, India) (Figure. 2). For this test, slurry was prepared by mixing sand particles and water and taken in the hopper. Square samples of dimensions $25 \times 25 \mathrm{~mm}$ was placed in the sample holder. Samples were eroded by flow of erodent discharge through a nozzle of $4 \mathrm{~mm}$ diameter. Impingement angles were changed by adjusting the sample holder at different angles $\left(30^{\circ}, 45^{\circ}, 60^{\circ}\right.$ and $\left.75^{\circ}\right)$. The strike was applied for $10 \mathrm{~min}$. The weight loss was determined by the weighing the sample before and after the slurry erosion test. The slurry erosion rate was calculated by dividing weight loss of samples with the time taken to perform an experiment i.e. $10 \mathrm{~min}$.

\subsubsection{Electrochemical tests}

The electrochemical or corrosion tests were conducted by using Potentiostat. It consists of three electrode namely working Electrode, a Reference Electrode and an Auxiliary or Counter electrode (Figure 3). A Potentiostat measures the current and voltage between the Working Electrode and the Reference Electrode. Both electrodes were dipped into an electrochemical cell having electrolyte of $3.5 \mathrm{wt} \% \mathrm{NaCl}$ solution. The working electrode was the sample itself whose corrosion potential had to be measured. The samples were prepared to a size of $1 \mathrm{~cm} \times 2.4 \mathrm{~cm}$ and were covered from all sides except for the side whose potential was to be determined.

\subsubsection{Scratch Test}

The scratch test was performed on the samples which were eroded under various conditions mentioned in Taguchi analysis of $\mathrm{CrN}$ coated samples. The test was conducted on a Scratch Tester (Model TR11, Ducom, India) (Figure 4). The samples were held in the machine vice and an indenter was made to scratch the samples for a particular stroke length and force. A graph between Traction force and stroke length was obtained from the computer attached to the machine.

\subsubsection{XRD analysis}

The XRD analysis of the samples eroded under steady state conditions. The test was performed on XRD machine (Figure 5 (a) and (b)). X- rays penetrated the 
both coated and uncoated samples at angles between $0^{\circ}$ to $90^{\circ}$ and graphs showing various peaks were obtained.

\section{RESULTS AND DISCUSSION}

\subsection{Corrosion measurement}

Corrosion has a great influence on the power consumption of the centrifugal pumps. Severe corrosion like pitting corrosion causes excessive power loss inside the impeller. Due to this power requirement of the pump increases and the overall life of the impeller goes down. The corrosion potentials of coated and uncoated sample are presented in Table 1. It is evident from Table 1 that the corrosion potential of uncoated AISI 304 steel samples was greater than the worn out coated samples, indicating that the fresh AISI 304 steel had lesser chance of being corroded. It was due to thin protective film of chromium, which was in intact state, over the entire steel specimen. Corrosion potential can be taken as a measure of corrosion resistance. Also among the worn out coated samples $200 \mathrm{~nm}$ and $150 \mathrm{~nm}$ coated samples exhibited the highest corrosion potential of $-310 \mathrm{mV}$ and $-261 \mathrm{mV}$ respectively. It was followed by $100 \mathrm{~nm}$ and $50 \mathrm{~nm}$ coated samples having the corrosion potentials of -255 $\mathrm{mV}$ and $-215 \mathrm{mV}$ respectively. The graphs in figure 6 indicated that greater the coating thickness of the worn out higher is its corrosion potential. So $150 \mathrm{~nm}$ coated samples have the highest corrosion resistance in sea water environment. Similar conclusions were obtained by Ortega et.al. [19] in which they deposited $\mathrm{Cr} / \mathrm{CrN}$ multilayer coating on AISI-304 stainless steel using slurry cell. They concluded that $\mathrm{Cr} / \mathrm{CrN}$ multilayer coating offered protection against pure corrosion and pure erosion and due to synergy. Corrosion potential along with average current density gives a more correct picture of the corrosive behaviour. While the corrosion potential is that threshold value of the potential which must be attained in order to initiate corrosion, the average current density of the anodic curves tells the intensity of corrosion in the given samples. The corrosion potential depends primarily on the coating constituents, while average current density depends on the salt concentration in water and on coating thickness. Again, from Table 1, it was also observed that the average current density decreased as coating thickness increased. Uncoated and eroded AISI-304 stainless steel indicated highest current density. Lower the value of current density better was the corrosion resistance [6]. It can also be noticed from figure 6 that the entire specimen have similar cathodic curves. However samples with different thickness of coating exhibit different anodic behaviour. It is also observed that the slope of anodic curve for uncoated samples is greater than that for the $\mathrm{CrN}$ coated samples indicating enhanced anodic dissolution in case of bare 304 steel. Greater the magnitude of corrosion potential $\left(\mathrm{E}_{\text {corr }}\right)$ greater is the area under anodic curve, indicating higher anodic dissolution. Hence anodic dissolution is higher in case of uncoated 304 steel as compared to the coated samples. Among the coated samples $150 \mathrm{~nm} \mathrm{CrN}$ coated sample depicted the lowest anodic dissolution and hence a better corrosion resistance. The corrosion potential was highly dependent on erodent discharge. Greater the erodent discharge, smaller is the corrosion potential. A high erodent discharge, as in first case, rendered the 50 $\mathrm{nm}$ coated sample more susceptible to corrosion. It was due to the fact that a higher erodent discharge not only eroded the coating at a faster rate but also accelerated the depletion of chromium from base metal. Moreover at this discharge maximum erosion was obtained due to which depletion of coating was accelerated. Corrosion potential was also related to combination of one or more significant factors. It means that it can be correlated with mass loss or erosion rate. Greater the mass loss, lesser is the corrosion potential.

Even in case of small hole or groove formation at low velocities the corrosion potential especially the pitting potential decreases. Due to this pitting corrosion is initiated in the presence of aggressive atmosphere like that of chloride ions.

\subsection{Measurement of coefficient of friction}

The Coefficient of friction has a great effect on the power consumption in a centrifugal pump. As the COF increases, the relative velocity of the fluid at the outlet vane decreases and power consumption increases. So measurement of COF of coatings is quite significant. Hence, the test for evaluating coefficient of friction was conducted using Scratch tester. The sample was loaded in the clamp (vice) and as the indenter scratched for a stroke length of $10 \mathrm{~mm}$.

Figure 7 indicated variation of coefficient of friction (COF) for different fresh (un-eroded) samples of varying thickness at loads of $10 \mathrm{~N}, 20 \mathrm{~N}$ and $30 \mathrm{~N}$. Hence, it can be seen that coefficient of friction decreased as the coating thickness increased. The generation of a smoother surface with increase in coating thickness is attributed to lesser coating defects like porosity and the development of better coating properties like hardness and work hardness and work hardening capability. After that, the coated samples were eroded and COF of the samples eroded at various conditions of coating thickness, impact velocity, impingement angle and erodent discharge were calculated at a constant load of $10 \mathrm{~N}$. A graph involving the variation of the Traction force with respect to stroke length was obtained (Figure 8). The Traction force can be 
taken as an indicative of COF. Erodent discharge has an important influence on the $\mathrm{COF}$ or the traction force. A high erodent discharge causes more material removal. A high erodent discharge can also cause the erodent particles to embed into the coating or into the base metal itself. Both these factors cause an increase in the coefficient of friction, as seen in $100 \mathrm{~nm}$ coated sample. Also at an erodent discharge of $200 \mathrm{gm} / \mathrm{min}$, a minimum erosion rate was obtained. The result was indicated as decrement in COF as evident from $50 \mathrm{~nm}$ coated sample. COF can be related to a combination of one or more significant factors. This indicated that coefficient of friction was correlated with erosion rate or mass loss. From Table 2 it was quite clear that with increase in mass loss there was an increase in COF. The exception to this was the first sample in which less mass loss in this sample could be due to synergy (antagonistic). The result was of practical essence and it signified that with an increase in operating period of the impeller, COF tended to increase which led to an increase in operating cost of the pump. This cost was nullified by the increase in life the impeller. COF of the coating depended on the mechanical properties like adhesion and density. Dense coating led to better anti corrosion properties and lower coefficient of friction [20].

\subsection{XRD analysis}

XRD analysis of the CrN coated samples was performed. Since XRD was performed on the entire sample its pattern indicated number of peaks corresponding to the elements present in both the base metal and in coating. Maximum number of peaks was displayed in the analysis of $100 \mathrm{~nm}$ coated samples (6 peaks) and $150 \mathrm{~nm}$ coated samples ( 7 peaks). Because the sample was eroded in $3.5 \mathrm{wt} \%$ saline slurry, a peak corresponding to $\mathrm{NaCl}$ was also obtained at a $2 \theta$ value of $31^{\circ}$ approx. since the XRD pattern was of the entire sample a peak corresponding to $\mathrm{Ni}$ present in base metal was obtained at $2 \theta$ value of $44^{\circ}$ approx. having (111) plane. An XRD analysis of $100 \mathrm{~nm}$ eroded sample was shown in Figure 9. Further, it can be seen from the XRD pattern between $2 \Theta$ and peak height (in counts per second) that the most prominent peak was at $2 \Theta$ approximately equal to $43.5^{\circ}$ and corresponds to Chromium nitride $(\mathrm{CrN})$ and $\mathrm{Cr}_{2} \mathrm{~N}$. It was evident from Table 3 that the height of the $\mathrm{CrN}$ and $\mathrm{Cr}_{2} \mathrm{~N}$ peak was essentially a function of the most important factor, that is, the erodent discharge. Such a fact has been observed in case of $100 \mathrm{~nm}$ coating thickness with $160 \mathrm{gm} / \mathrm{min}$ erodent discharge at $15 \mathrm{~m} / \mathrm{s}$ impact velocity, where small erodent discharge and impact velocity led to the least depletion of Chromium nitride $(\mathrm{CrN})$ and $\mathrm{Cr}_{2} \mathrm{~N}$. Therefore highest peak height was obtained in this case (Table 3). As the impact velocity was increased there is an increase in erosion rate as evident from steady state results. It means that with increase in impact velocity more depletion of the $\mathrm{CrN}$ and $\mathrm{Cr}_{2} \mathrm{~N}$ coating due to which peak height in case of $100 \mathrm{~nm}, 150 \mathrm{~nm}$ and $200 \mathrm{~nm}$ goes on reducing. In case, the erodent discharge was not same, the peak height then depended on the most significant factor in the decreasing order of significance, that is erodent discharge > coating thickness> impingement angle > impact velocity. That means the peak height could be related to mass loss. By measuring the peak height we can estimate the depletion of coating under the given condition. It is also useful to get knowledge about the effectiveness of the $\mathrm{CrN}$ coatings at various thicknesses. More material depletion or removal takes place at smaller angles due to large shear stresses involved. That is why an angle of $45^{\circ}$ has been chosen so as to obtain a maximum mass loss. If one or more factors become equally dominant then the peak height is interplay of these two factors and intermediate results are obtained.

\section{CONCLUSIONS}

The following conclusions can be drawn on the basis of erosive corrosive wear of the single layer $(\mathrm{CrN})$ coatings of various thicknesses (50nm, 100nm, 150nm and 200nm) on AISI 304 Stainless Steel and uncoated 304 steel by setting the various parameters such as coating thickness, impact velocity, impingement angle and erodent discharge at significant levels:

1. Corrosion potential along with average current density gives a more correct picture of the corrosive behaviour. While the corrosion potential is that threshold value of the potential which must be attained in order to initiate corrosion, the average current density of the anodic curves tells the intensity of corrosion in the given samples.

2. Corrosion potential can be taken as a measure of corrosion resistance. Also among the worn out coated samples $200 \mathrm{~nm}$ and $150 \mathrm{~nm}$ coated samples exhibited the highest corrosion potential of -310 $\mathrm{mV}$ and $-261 \mathrm{mV}$ respectively. It was followed by $100 \mathrm{~nm}$ and $50 \mathrm{~nm}$ coated samples having the corrosion potentials of $-255 \mathrm{mV}$ and $-215 \mathrm{mV}$ respectively. Greater the coating thickness of the worn out higher is its corrosion potential and more is the corrosion resistance.

3. Corrosion potential can be related to mass loss or erosion rate. More mass loss means mass loss of either the corrosion resistant $\mathrm{CrN}$ coating or the base metal underneath or both. In both these cases the corrosion potential of the sample decreased. In case where the erosion of base metal took place due to swiping off of the coating it is the protective 
chromium layer which gets depleted leaving the material susceptible to corrosion.

4. Corrosion potential along with average current density gives a more correct picture of the corrosive behaviour. While the corrosion potential is that threshold value of the potential which must be attained in order to initiate corrosion, the average current density of the anodic curves tells the intensity of corrosion in the given samples. The corrosion potential depends primarily on the coating constituents, while average current density depends on the salt concentration in water and on coating thickness. It was also observed that the average current density decreased as coating thickness increased.

5. The entire specimens have similar cathodic curves. However samples with different thickness of coating exhibit different anodic behaviour. It is also observed that the slope of anodic curve for uncoated samples is greater than that for the $\mathrm{CrN}$ coated samples indicating enhanced anodic dissolution in case of bare 304 steel. Greater the magnitude of corrosion potential $\left(\mathrm{E}_{\text {corr }}\right)$ greater is the area under anodic curve, indicating higher anodic dissolution. Hence anodic dissolution is higher in case of uncoated 304 steel as compared to the coated samples.

6. The corrosion potential was highly dependent on erodent discharge. Greater the erodent discharge, smaller is the corrosion potential.

7. Erodent discharge has a very important influence on the coefficient of friction. Higher the erodent discharge more is the number of particles embedded into the coating or directly into the base

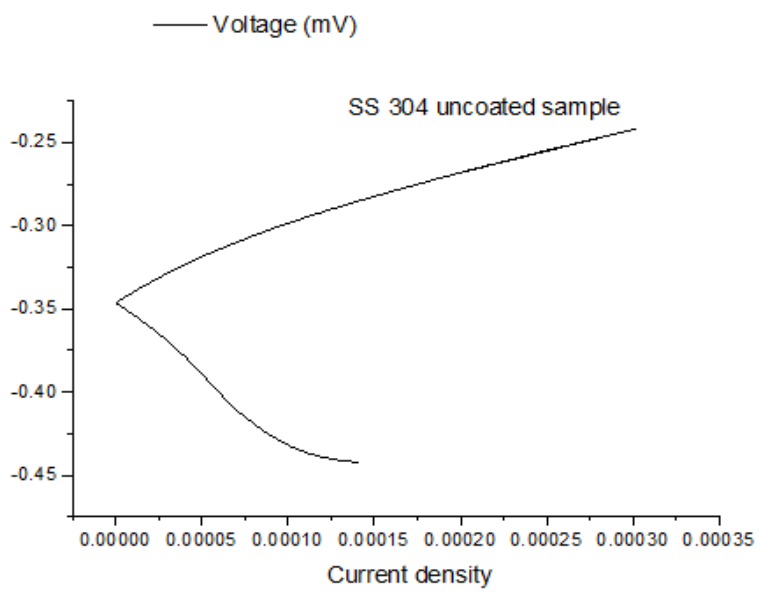

metal and so higher is the COF for those samples. With increase in erodent discharge, rate of work hardening also increases which may also contribute to increase in $\mathrm{COF}$.

8. Both the $\mathrm{CrN}$ and $\mathrm{Cr}_{2} \mathrm{~N}$ (200) compounds have been found in XRD analysis of the samples. Out of these $\mathrm{Cr}_{2} \mathrm{~N}$ dominated as it has large number of peaks at various $2 \Theta$ positions and that its formation did not affect the wear performance of the coatings. Both the $\mathrm{CrN}$ and $\mathrm{Cr}_{2} \mathrm{~N}$ (200) compounds were collectively responsible for enhancement of erosive corrosive wear resistance.

9. Height of the peaks in XRD pattern was a result of the dominance of one or more factors in the decreasing order of significance, that is erodent discharge > coating thickness $>$ impingement angle $>$ impact velocity. This was the same order of significance as obtained by using Taguchi methodology. In case two or more factors became equally significant then peak height was interplay of both the significant factors and intermediate results were obtained.

10. Erodent discharge played a crucial role in determining the corrosion potential of the samples. Greater the erodent discharge, more was the depletion of corrosion resistant $\mathrm{CrN}$ and $\mathrm{Cr}_{2} \mathrm{~N}$ (200) coating and higher were the chances of getting corroded. In many cases, high erodent discharge swiped off the coating from a particular area of the sample and causes depletion of the thin protective layer of chromium on the steel surface. This in turn decreased the corrosion potential and again increased the possibility of corrosion in steels.

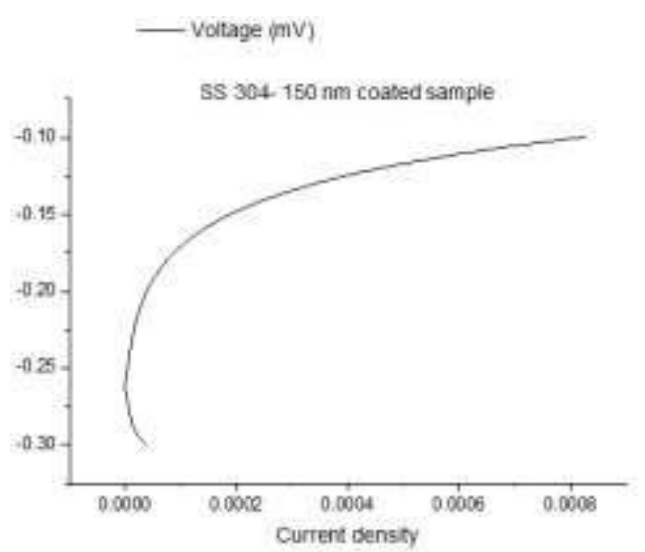


- voltage (nv)

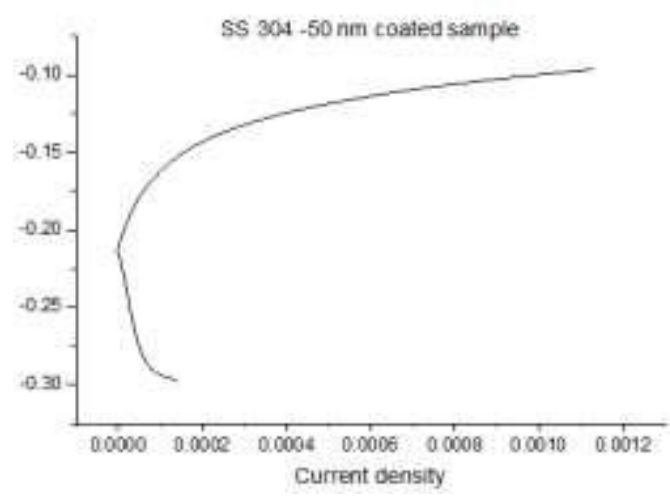

Fig.2: Tafel plots for uncoated and single layer CrN coated 304 steel Counts per second
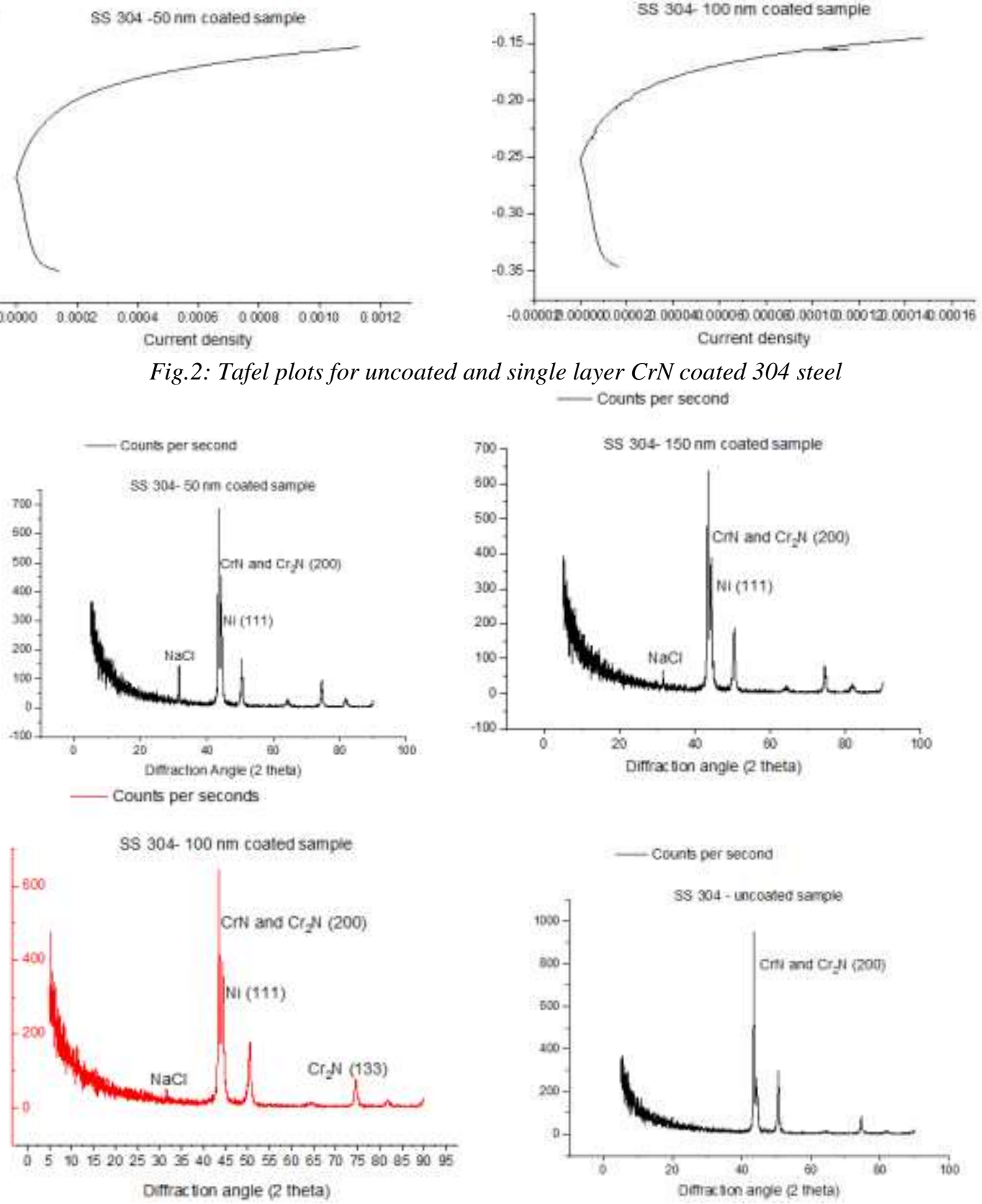
Current density

Counts per second
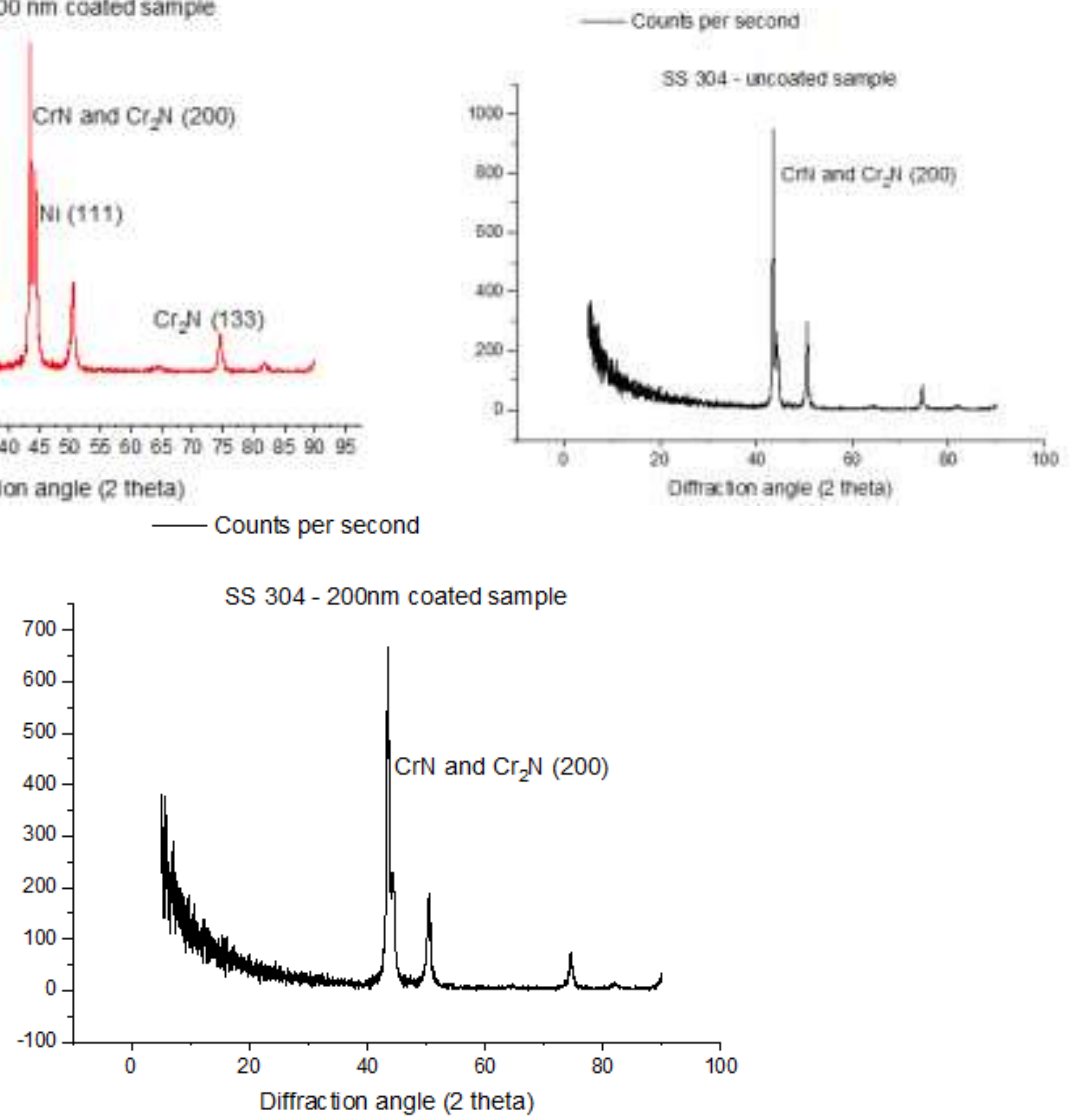

Fig.3: XRD patterns of various worn out samples 


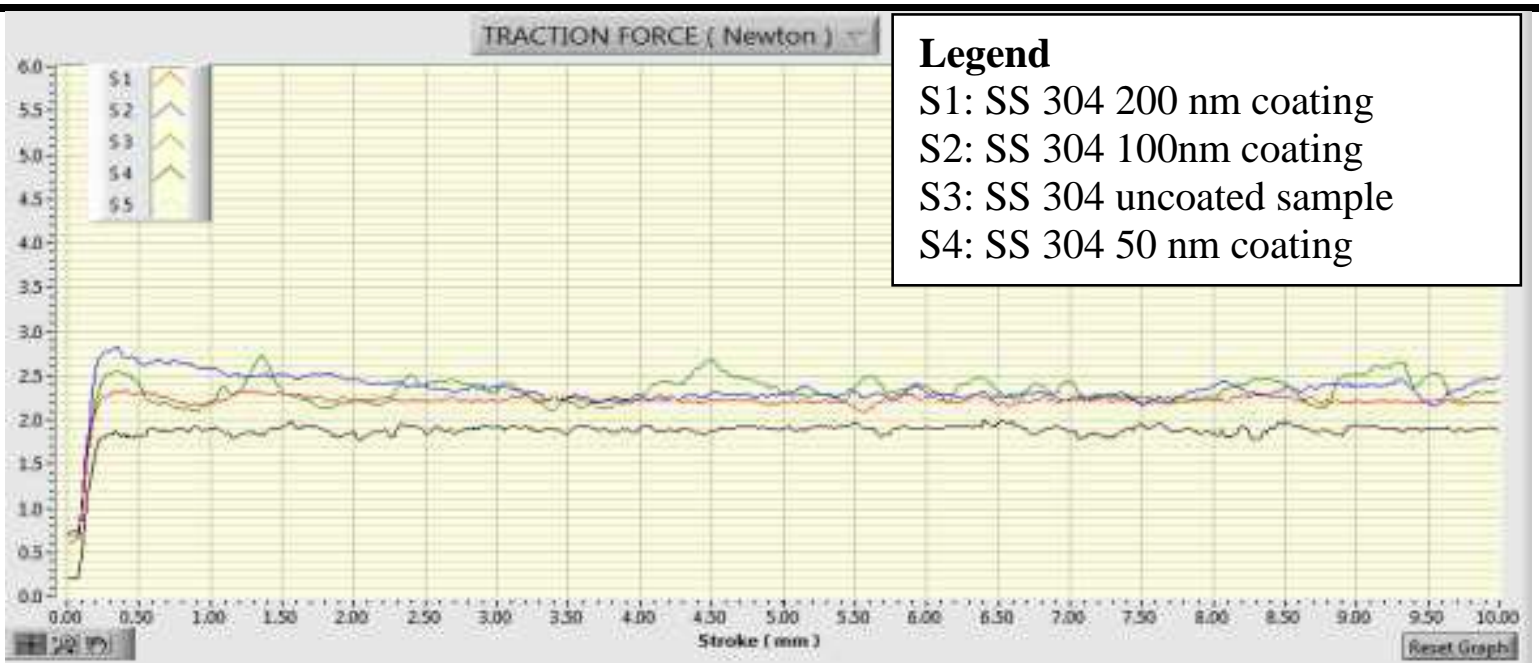

Fig.4: Variation of Traction Force with respect to Stroke length at constant load of $10 \mathrm{~N}$

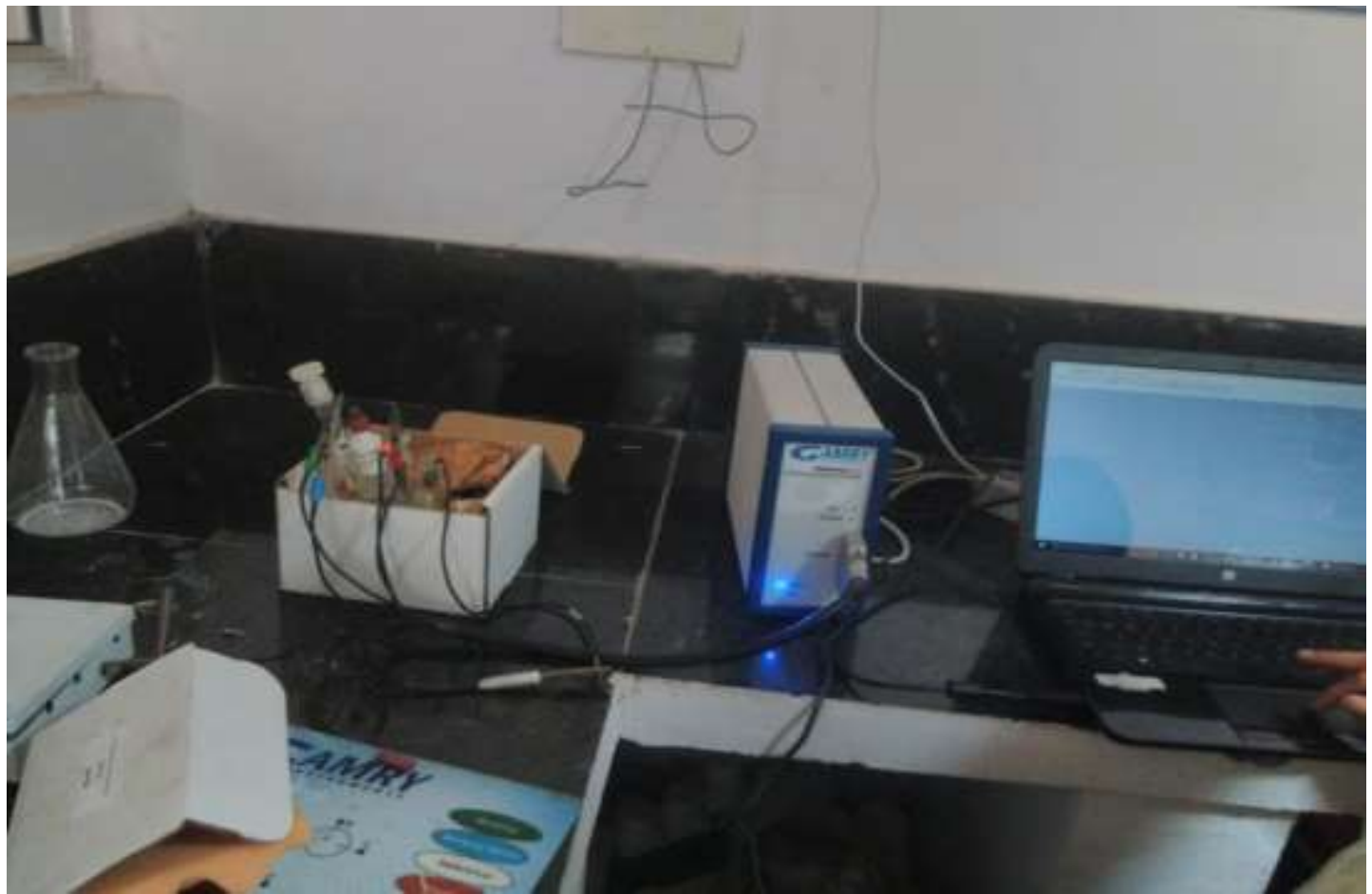

Fig.5: Diagram of Test set up of a Potentiostat

Table.1: Corrosion potential of steel samples under various conditions

\begin{tabular}{|c|l|l|l|l|l|l|l|}
\hline S. No. & $\begin{array}{c}\text { Coating } \\
\text { thickness } \\
(\mathbf{n m})\end{array}$ & $\begin{array}{c}\text { Impact } \\
\text { velocity } \\
(\mathbf{m} / \mathbf{s e c})\end{array}$ & $\begin{array}{c}\text { Impingement } \\
\text { angle (degrees) }\end{array}$ & $\begin{array}{c}\text { Erodent } \\
\text { discharge } \\
(\mathbf{g m} / \mathbf{m i n})\end{array}$ & $\begin{array}{l}\text { Corrosion } \\
\text { potential } \\
(\mathbf{m V}) \\
\boldsymbol{E}_{\text {corr }}\end{array}$ & $\begin{array}{l}\text { Current } \\
\text { density } \\
\left(\mathbf{A} / \mathbf{c m}^{2}\right)\end{array}$ & $\begin{array}{l}\text { Erosion } \\
\text { rate }\end{array}$ \\
\hline 1 & 50 & 20 & 60 & 240 & -215 & $1.54 \times 10^{-6}$ & 0.0030 \\
\hline 2 & 100 & 25 & 60 & 200 & -255 & $2.82 \times 10^{-7}$ & 0.0012 \\
\hline 3 & 150 & 10 & 60 & 280 & -261 & $2.40 \times 10^{-7}$ & 0.0011 \\
\hline 4 & 200 & 15 & 60 & 160 & -310 & $3.20 \times 10^{-7}$ & 0.0012 \\
\hline 5 & Uncoated 304 steel & & -350 & $5.01 \times 10^{-6}$ & \\
\hline
\end{tabular}


Table.3: Various erosion conditions of samples and height of $\mathrm{CrN}$ and $\mathrm{Cr}_{2} \mathrm{~N}(200)$ peak

\begin{tabular}{|c|l|l|l|l|l|l|}
\hline S. No. & $\begin{array}{c}\text { Coating } \\
\text { thickness } \\
(\mathbf{n m})\end{array}$ & $\begin{array}{c}\text { Impact } \\
\text { velocity } \\
(\mathbf{m} / \mathbf{s e c})\end{array}$ & $\begin{array}{c}\text { Impingement } \\
\text { angle (degrees) }\end{array}$ & $\begin{array}{c}\text { Erodent } \\
\text { discharge } \\
(\mathbf{g m} / \mathbf{m i n})\end{array}$ & $\begin{array}{l}\text { Position of the } \\
\text { prominent } \\
\text { or 28 }\end{array}$ & $\begin{array}{c}\text { Height of } \\
\text { peak } \\
\text { peak } \\
\text { in cts })\end{array}$ \\
\hline 1 & 50 & 10 & 45 & 160 & 43.5034 & 637.87 \\
\hline 2 & 100 & 15 & 45 & 160 & 43.5108 & 623.59 \\
\hline 3 & 150 & 20 & 45 & 160 & 43.4774 & 617.42 \\
\hline 4 & 200 & 25 & 45 & 160 & 43.4509 & 614.37 \\
\hline
\end{tabular}

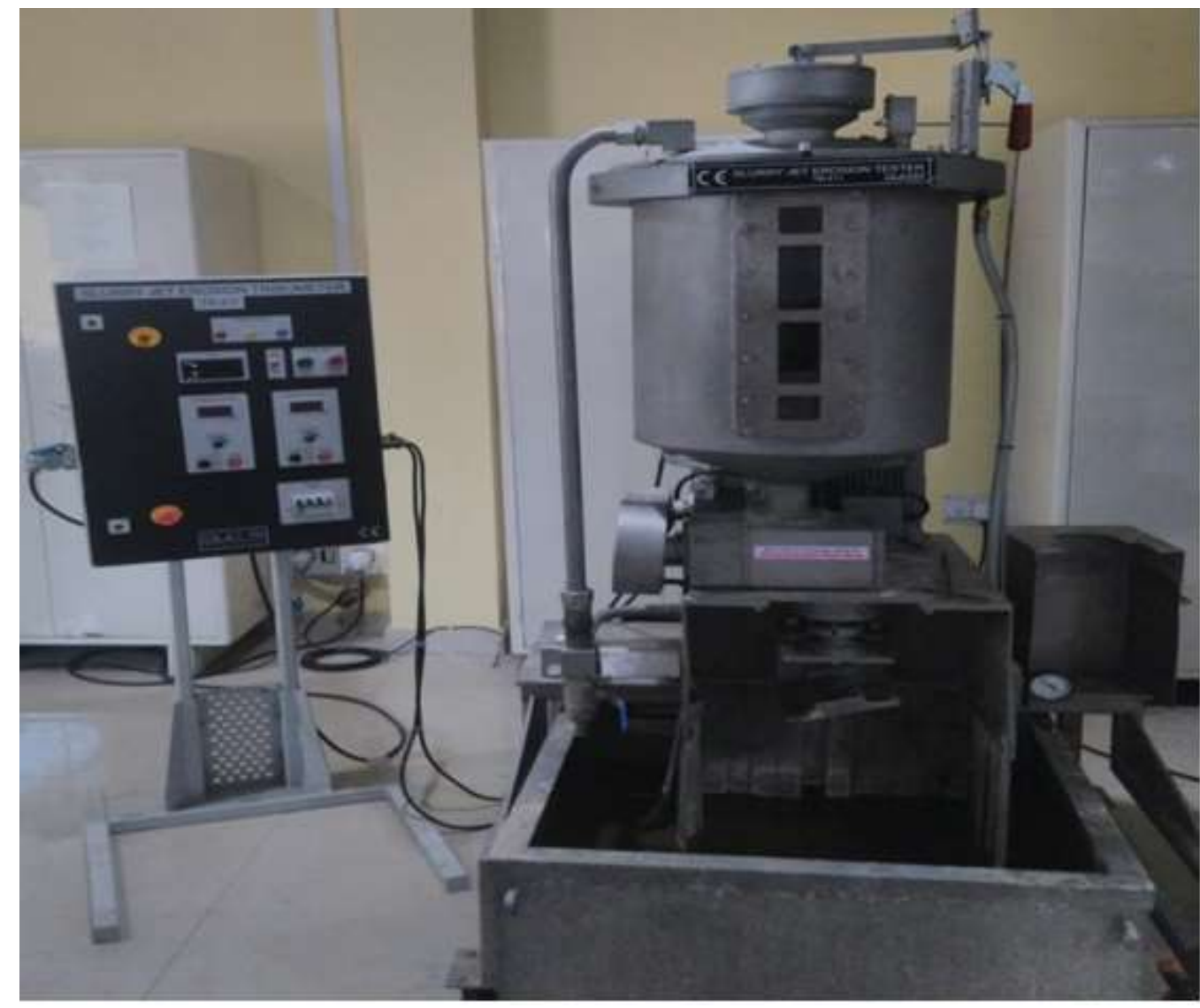

Fig.6: Test setup of Slurry Jet Erosion Tester

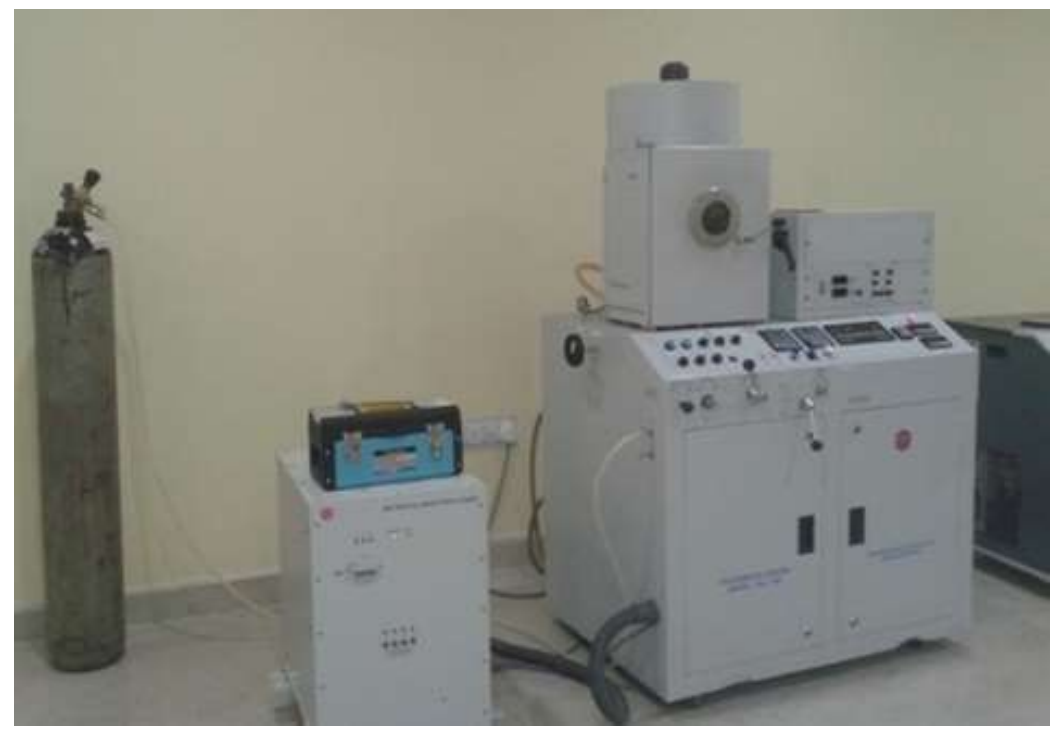

Fig.7: Thermal/E-beam PVD Coating Unit 
Table.2: Average Traction force for various steel samples in different conditions

\begin{tabular}{|c|l|l|l|l|l|l|}
\hline S. No. & $\begin{array}{c}\text { Coating } \\
\text { thickness } \\
(\mathbf{n m})\end{array}$ & $\begin{array}{c}\text { Impact } \\
\text { velocity } \\
(\mathbf{m} / \mathbf{s e c})\end{array}$ & $\begin{array}{c}\text { Impingement } \\
\text { angle (degrees) }\end{array}$ & $\begin{array}{c}\text { Erodent } \\
\text { discharge } \\
(\mathbf{g m} / \mathbf{m i n})\end{array}$ & $\begin{array}{c}\text { Average } \\
\text { Traction } \\
\text { force }(\mathbf{N})\end{array}$ & $\begin{array}{l}\text { Erosion } \\
\text { rate or } \\
\text { mass loss }\end{array}$ \\
\hline 1 & 50 & 15 & 45 & 200 & 1.90 & 0.0017 \\
\hline 2 & 100 & 10 & 45 & 240 & 2.40 & 0.0018 \\
\hline 3 & 150 & 25 & 45 & 160 & 2.35 & 0.0012 \\
\hline 4 & 200 & 20 & 45 & 280 & 2.25 & 0.0011 \\
\hline 5 & Uncoated 304 steel & & 2.43 & \\
\hline
\end{tabular}

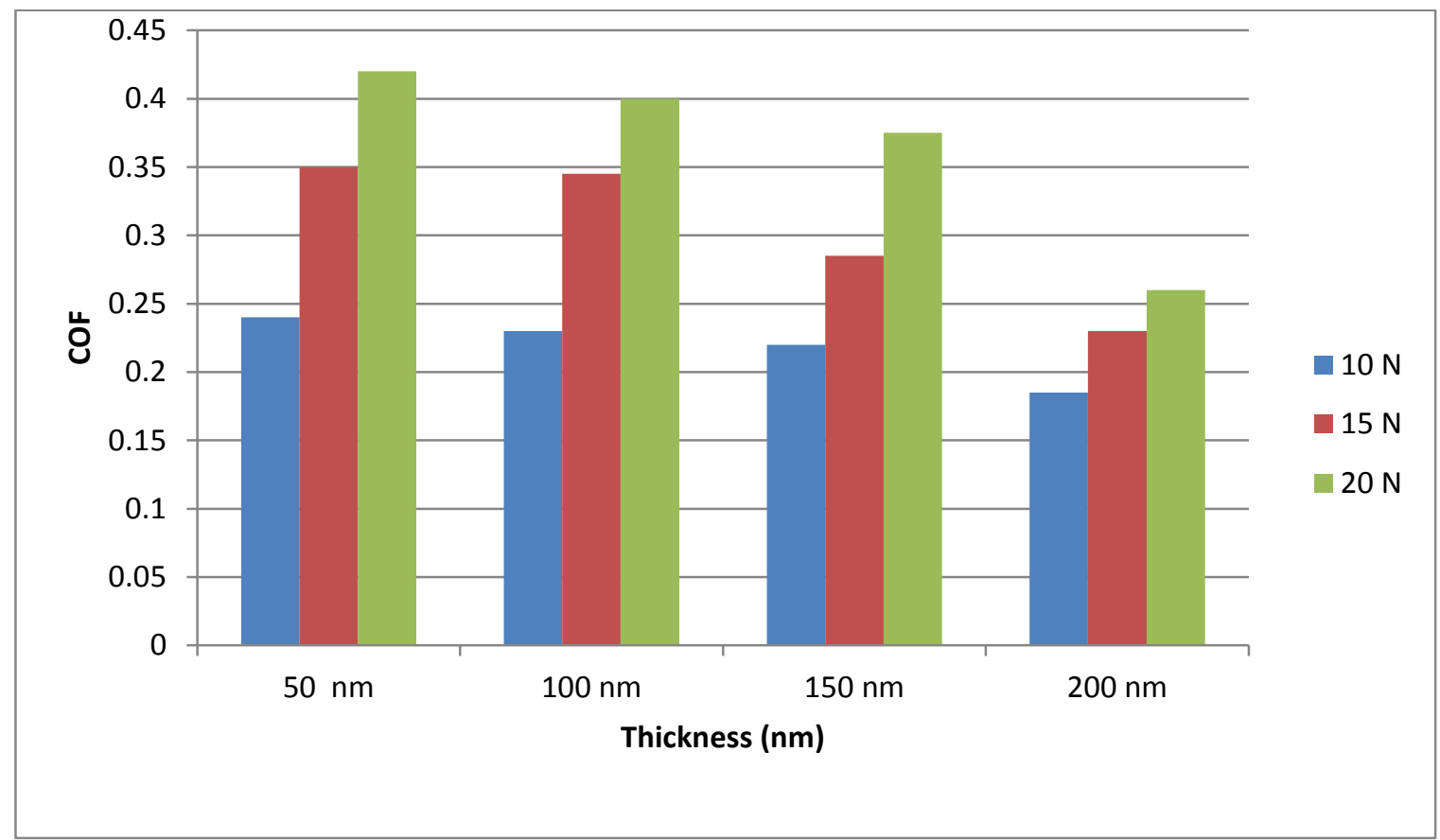

Fig.8: Variation of COF over different loads and at various coating thicknesses

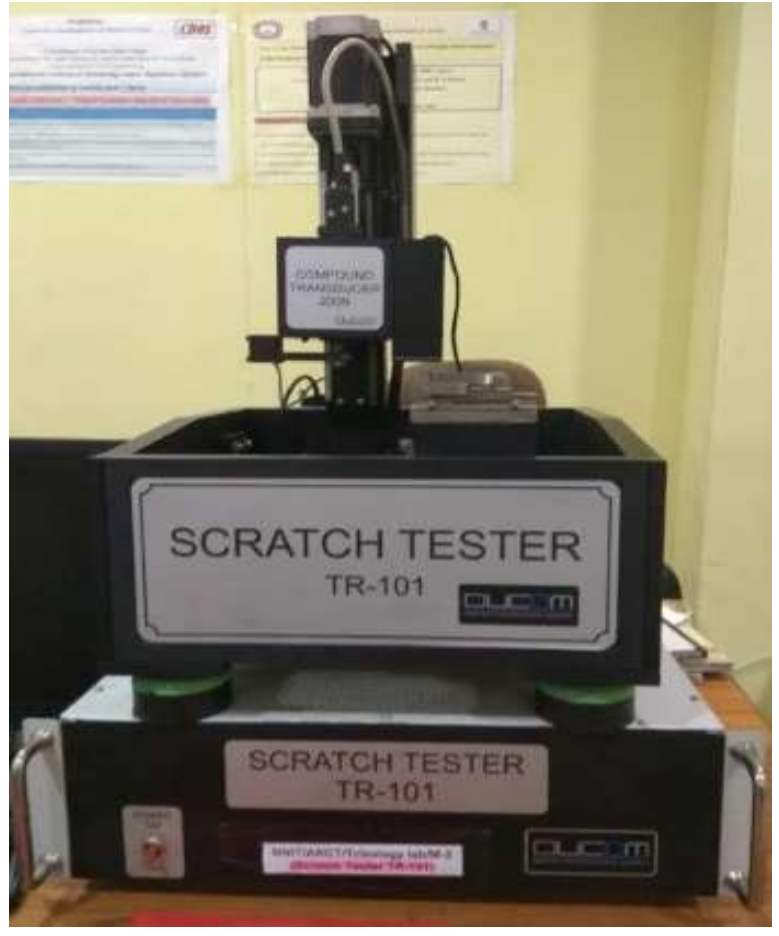

Fig.9: Test setup of Scratch Tester

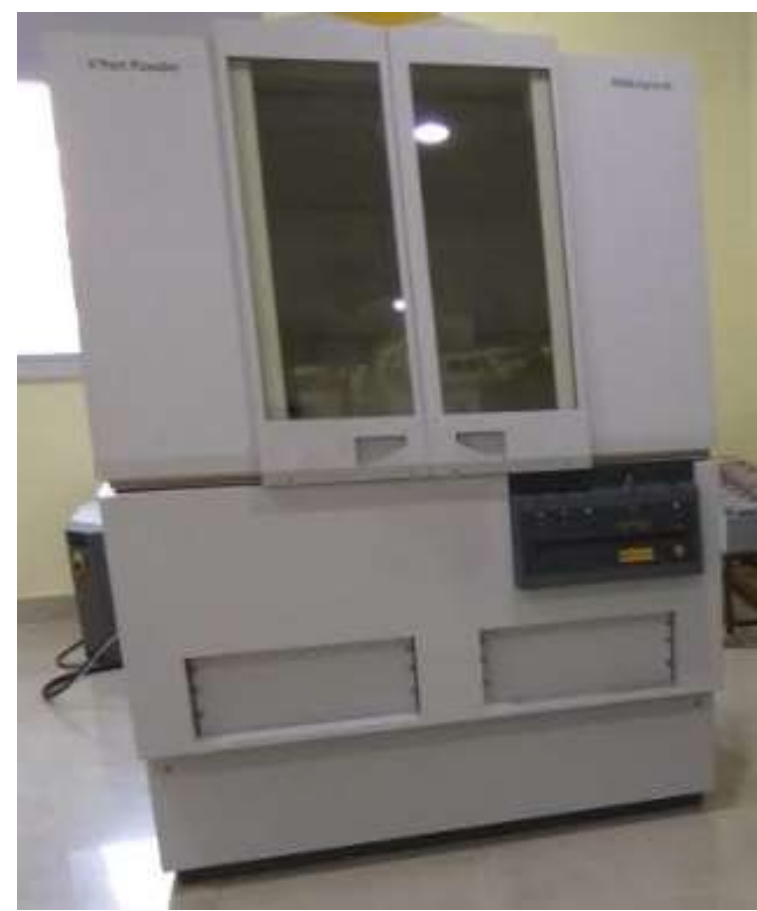

(a) Test setup of XRD machine 


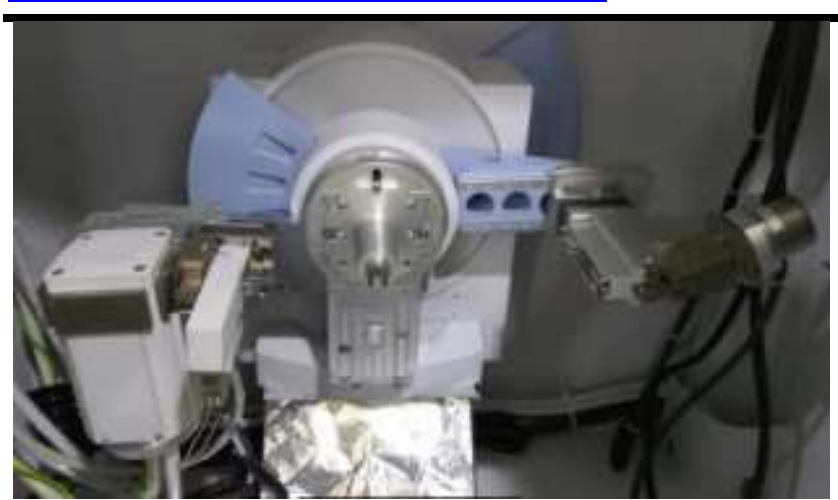

(B) Inside of an XRD machine

Fig.10: XRD machine

\section{REFERENCES}

[1] Zhang, G. A., Xu, L. Y., Cheng, Y. F. (2009) Investigation of erosion-corrosion of 3003 aluminum alloy in ethylene glycol-water solution by impingement jet system, Corros. Sci. 51, pp 283-290.

[2] Shrestha, S., Hodgkiess, T., Neville, A. (2005) Erosion-corrosion behavior of high-velocity oxyfuel $\mathrm{Ni}-\mathrm{Cr}-\mathrm{Mo}-\mathrm{Si}-\mathrm{B}$ coatings under highvelocity seawater jet impingement, Wear 259, pp 208-218

[3] Saha, G. C., Khan, T. I. G. A. Zhang, (2011), Erosion-corrosion resistance of microcrystalline and near-nanocrystalline $\mathrm{WC}-17 \mathrm{Co}$ high velocity oxy-fuel thermal spray coatings, Corros. Sci. 53, pp 2106-2114.

[4] Hong, S., Wu, Y., Zhang, J., Zheng, Y., Qin, Y., Lin, J. (2015), Effect of ultrasonic cavitation erosion on corrosion behavior of high-velocity oxygen-fuel (HVOF) sprayed near-nanostructured WC-10Co-4Cr coating, Ultrason. Sonochem. 27, pp 374-378.

[5] Zhao, Y., Zhou, F., Yao, J., Dong, S., Li, N., (2015), Erosion-corrosion behaviour and corrosion resistance of AISI 316 stainless steel in flow jet impingement, Wear 328-329, pp 464-474.

[6] Lin, C. K., Hsu, C. H., Cheng, Y. H., Liang, O. K., Lee, S. L. (2015), A study on the corrosion and erosion behavior of electroless nickel and TiAlN/ZrN duplex coatings on ductile iron, Appl. Surf. Sci. 324, pp 13-19.

[7] Neville, A., Wang, C. (2009), Erosion-corrosion of engineering steels - Can it be managed by use of chemicals, Wear 267, pp 2018-2026.

[8] Pantoja, M., Abenojar, J., Martínez, M. A., Velasco, F. (2016), Silane pretreatment of electrogalvanized steels: Effect on adhesive properties, International Journal of Adhesion and Adhesives 65, pp 54-62.

[9] Pantoja, M., Martínez, M. A., Abenojar, J., Encinas, N., Ballesteros, Y. (2011), Effect of $\mathrm{EtOH} / \mathrm{H} 2 \mathrm{O}$ ratio and $\mathrm{pH}$ on bis-sulfur silane solutions for electrogalvanized steel joints based on anaerobic adhesives, The Journal of Adhesion 87 (7-8), pp 688-708.

[10] Martinez, M. A., Calabrés, R., Abenojar, J., Velasco, F., (2008), Sintered High Carbon Steels: Effect of Thermomechanical Treatments on their Mechanical and Wear Performance, Materials Science Forum 591, pp 271-276.

[11] Pantoja, M., Martínez, M. A., Abenojar, J., Velasco, F., Real, J. C. (2010), Structural and mechanical characterization of $\gamma$ methacryloxypropyltrimethoxysilane (MPS) on $\mathrm{Zn}$ electrocoated steel Journal of Adhesion Science and Technology 24 (11-12), pp 1885-1901.

[12]Pantoja, M., Velasco, F., Broekema, D., Abenojar, J., Real, J. C. (2011), The influence of $\mathrm{pH}$ on the hydrolysis process of $y$ methacryloxypropyltrimethoxysilane, analyzed by FT-IR, and the silanization of electrogalvanized steel, Journal of Adhesion Science and Technology 24(6), pp 1131-1143.

[13] Recco, A. A., Lopez, C. D., Bevilacqua, A. F., da Silva, F., Tschiptschin, A. P. (2007), Improvement of the slurry erosion resistance of an austenitic stainless steel with combinations of surface treatments: Nitriding and TiN coating, Surf. Coat. Tech. 202, pp 993-997.

[14] Hu, X., Alzawai, K., Gnanavelu, A., Neville, A., Wang, C., Crossland, A., Martin, J. (2011), Assessing the effect of corrosion inhibitor on erosion-corrosion of API-5L-X65 in multi-phase jet impingement conditions, Wear 271, pp 1432- 1437.

[15] Yao, J., Zhang, B. Z., Fan, J. R. (2000), Investigation of a new protection method for protecting tube from erosion in gas-particle flows, $\mathrm{J}$. Therm. Sci. 9(2), pp 158-162.

[16] Wood, R. J. K. (2007) Tribo-corrosion of coatings: a review, J. Phys. D. Appl. Phys. 40(18), pp 55025521.

[17] Ye, Y., Wang, Y., Chen, H., Li, J., Yao, Y. (2015) Doping carbon to improve the tribological performance of $\mathrm{CrN}$ coatings in seawater, Tribol. Int. 90, pp 362-371.

[18] Shan, L., Wang, Y., Li, J., Jiang, X., Chen, J. (2015) Improving tribological performance of $\mathrm{CrN}$ coatings in seawater by structure design, Tribol. Int. 8278-88.

[19] Ortega, J. A., Ocampo-Carmona, L. M., SuarezBustamante, F. A., Olaya-Florez, J. J. (2012) 
Erosion-corrosion wear of $\mathrm{Cr} / \mathrm{CrN}$ multi-layer coating deposited on AISI-304 stainless steel using the unbalanced magnetron (UBM) sputtering system. Wear 290-291, pp 149-153.

[20] De Souza, V. A., Neville, A. (2003) Corrosion and erosion damage mechanisms during erosioncorrosion of WC-Co-Cr cermet coatings, Wear 255, pp 146-156. 